\title{
Cytoprotective effects of esculetin against oxidative stress are associated with the upregulation of Nrf2-mediated NQO1 expression via the activation of the ERK pathway
}

\author{
MIN HO HAN ${ }^{1}$, CHEOL PARK $^{2}$, DAE-SUNG LEE ${ }^{1}$, SU-HYUN HONG ${ }^{3}$, IL-WHAN CHOI ${ }^{4}$, GI-YOUNG KIM ${ }^{5}$, \\ SUNG HYUN CHOI ${ }^{6}$, JUNG-HYUN SHIM ${ }^{7}$, JUNG-IL CHAE ${ }^{8}$, YOUNG HYUN YOO ${ }^{9}$ and YUNG HYUN CHOI ${ }^{3,10}$
}

\begin{abstract}
${ }^{1}$ Natural Products Research Team, National Marine Biodiversity Institute of Korea, Seocheon 325-902;
${ }^{2}$ Department of Molecular Biology, College of Natural Sciences and Human Ecology, Dongeui University, Busan 614-714; ${ }^{3}$ Department of Biochemistry, Dongeui University College of Korean Medicine, Busan 614-052;

${ }^{4}$ Department of Microbiology, College of Medicine, Inje University, Busan 608-756; ${ }^{5}$ Laboratory of Immunobiology, Department of Marine Life Sciences, Jeju National University, Jeju 690-756; ${ }^{6}$ Department of Safety and System Management, Korea Lift College, Geochang 670-802; ${ }^{7}$ Natural Medicine Research Institute, Department of Pharmacy, College of Pharmacy,

Mokpo National University, Jeonnam 534-729; ${ }^{8}$ Department of Dental Pharmacology, School of Dentistry,

BK21 Plus, Chonbuk National University, Jeonju 561-756; ${ }^{9}$ Department of Anatomy and Cell Biology,

Dong-A University College of Medicine and Mitochondria Hub Regulation Center, Busan 602-714;

${ }^{10}$ Blue-Bio Industry RIC and Anti-aging Research Center, Dongeui University, Busan 614-714, Republic of Korea
\end{abstract}

Received July 26, 2016; Accepted December 7, 2016

DOI: $10.3892 / \mathrm{ijmm} .2016 .2834$

\begin{abstract}
Esculetin, a coumarin derivative isolated from a variety of medicinal herbs, has been reported to possess multiple therapeutic and pharmacological actions. Although several studies have demonstrated the antioxidant activity of esculetin, its mechanisms of action have not been clearly established. The aim of this study was to evaluate the effects of esculetin against hydrogen peroxide $\left(\mathrm{H}_{2} \mathrm{O}_{2}\right)$-induced oxidative stress in $\mathrm{C} 2 \mathrm{C} 12$ myoblasts and to investigate the mechanisms involved in this process. Our data indicated that esculetin preconditioning significantly attenuated $\mathrm{H}_{2} \mathrm{O}_{2}$-induced growth inhibition and DNA damage and the apoptosis of $\mathrm{C} 2 \mathrm{C} 12$ cells by suppressing intracellular reactive oxygen species (ROS) accumulation. Treatment with esculetin effectively increased the phosphorylation of nuclear factor erythroid 2-related factor 2 (Nrf2) and the expression of NAD(P)H:quinone
\end{abstract}

Correspondence to: Dr Young Hyun Yoo, Department of Anatomy and Cell Biology, Dong-A University College of Medicine and Mitochondria Hub Regulation Center, 3-1 Dongdaesin-dong, Seo-gu, Busan 602-714, Republic of Korea

E-mail: yhyoo@dau.ac.kr

Dr Yung Hyun Choi, Department of Biochemistry, Dongeui University College of Korean Medicine, 42 San, Yangjung-dong, Busan 614-052, Republic of Korea

E-mail: choiyh@deu.ac.kr

Key words: esculetin, oxidative stress, reactive oxygen species, nuclear transcription factor erythroid 2-related factor 2, extracellular signal-regulated kinase, $\mathrm{NAD}(\mathrm{P}) \mathrm{H}$ :quinone oxidoreductase 1 oxidoreductase 1 (NQO1). Esculetin treatment also activated extracellular signal-regulated kinase (ERK), and pre-treatment with PD98059, an ERK-specific inhibitor, blocked esculetin-mediated phosphorylation of Nrf2 and the induction of NQO1 expression. In addition, the protective effects of esculetin against $\mathrm{H}_{2} \mathrm{O}_{2}$-induced $\mathrm{ROS}$ accumulation, apoptosis and growth inhibition were abrogated in the $\mathrm{C} 2 \mathrm{C} 12$ cells pre-treated with PD98059. Thus, the present study demonstrates that esculetin protects $\mathrm{C} 2 \mathrm{C} 12$ cells against oxidative stress-induced injury, possibly through the activation of the Nrf2/NQO1 pathway.

\section{Introduction}

It is well known that oxidative stress occurs as a result of excessive reactive oxygen species (ROS), such as singlet oxygen, superoxide anions, and hydrogen peroxide $\left(\mathrm{H}_{2} \mathrm{O}_{2}\right)$. These ROS cause irreversible damage to cellular components, including lipids, proteins, DNA, and other macromolecules, which has been linked to cell death $(1,2)$. ROS are also known to contribute to various pathological conditions, including cancer; inflammatory, neurodegenerative and cardiovascular diseases; and aging (3-5). Therefore, the human body has various defense systems against oxidative stress that are surpassed in extensive damage $(6,7)$. These mechanisms use antioxidant enzymes or antioxidant compounds. Among these systems, thenuclear transcriptionfactor erythroid 2-related factor 2 (Nrf2) signaling pathway has recently attracted interest as a candidate for protection from oxidative damage as it is involved in cellular antioxidant defenses $(8,9)$. $\mathrm{Nrf2}$ is an essential transcription factor that regulates a number of detoxifying and antioxidant defense genes by binding to antioxidant responsive elements (AREs) $(10,11)$. Under quiescent conditions, Nrf2-dependent transcription is suppressed by the 
negative regulator Kelch-like ECH-associated protein 1 (Keap1), which facilitates the degradation of Nrf2 through ubiquitinated proteasomal degradation $(12,13)$. Upon stimulation, Nrf2 escapes Keap1-mediated repression, translocates into the nucleus, and subsequently binds to AREs present in the promoter regions of an array of genes, including heme oxygenase-1 (HO-1) and $\mathrm{NAD}(\mathrm{P}) \mathrm{H}$ :quinone oxidoreductase 1 (NQO1), involved in cellular antioxidant defense $(14,15)$. HO-1 can catalyze the degradation of heme, resulting in the formation of the antioxidant bilirubin when biliverdin reductase is present $(16,17)$. NQO1, a cytosolic flavoprotein, facilitates the detoxification and excretion of endogenous and exogenous chemicals via a reduction reaction that converts quinones to hydroquinones, limiting the subsequent generation of ROS $(18,19)$.

Esculetin (6,7-dihydroxycoumarin) is a phenolic compound and derivative of coumarin $(20,21)$. This compound is found in many plants, such as Artemisia capillaris, Ceratostigma willmottianum and Citrus limonia that have been used in traditional Oriental herbal medicine for many decades $(22,23)$. Esculetin has been reported to have diverse pharmacological actions, including anti-neurotoxicity (24,25), anti-angiogenesis (26), anti-inflammatory $(27,28)$, and antitumor activities (29-32). More recently, esculetin has been shown to have beneficial effects on cellular oxidative stress (33-35). However, the inhibitory mechanisms of esculetin vis-à-vis the beneficial effect of esculetin against oxidative stress have not been fully studied to date. Therefore, in the present study, we evaluated the protective effects of esculetin on $\mathrm{H}_{2} \mathrm{O}_{2}$-induced oxidative stress and whether esculetin can activate Nrf2 signaling in mouse-derived C2C12 myoblasts.

\section{Materials and methods}

Reagents and antibodies. Esculetin (6,7-dihydroxycoumarin) was purchased from Sigma Chemical Co. (St. Louis, MO, USA), dissolved in dimethyl sulfoxide (DMSO, vehicle), and adjusted to final concentrations using complete culture medium. The final DMSO concentration was $<0.1 \%$ in all experiments. Dulbecco's modified Eagle's medium (DMEM), fetal bovine serum (FBS), and other tissue culture reagents were obtained from WelGENE Inc. (Daegu, Korea). $\mathrm{H}_{2} \mathrm{O}_{2}$, 3-(4,5-dimethylthiazol-2-yl)-2,5-diphenyltetrazolium bromide (MTT), $N$-acetyl-L-cysteine (NAC), 4',6-diamidino-2phenylindole (DAPI), propidium iodide (PI) and zinc protoporphyrin IX (ZnPP) were also purchased from Sigma Chemical Co. PD98059, an ERK inhibitor, was purchased from Calbiochem, Inc. (San Diego, CA, USA). 2',7'-Dichlorofluorescein diacetate (DCFDA) and an Annexin V-fluorescein isothiocyanate (FITC) apoptosis detection kit were purchased from Molecular Probes, Inc. (Eugene, OR, USA) and R\&D Systems Inc. (Minneapolis, MN, USA), respectively. Primary antibodies (Table I) were purchased from Santa Cruz Biotechnology, Inc. (Dallas, TX, USA), Cell Signaling Technology, Inc. (Danvers, MA, USA) and Abcam, Inc. (Cambridge, MA, USA). An enhanced chemiluminescence (ECL) kit and horseradish (HRP)-conjugated secondary antibodies were obtained from Amersham Life Science (Arlington Heights, IL, USA). All other chemicals not specifically mentioned here were purchased from Sigma Chemical Co.
Cell culture and viability assay. $\mathrm{C} 2 \mathrm{C} 12$ myoblasts obtained from the American Type CultureCollection(Manassas, VA,USA) were cultured in DMEM supplemented with $10 \%$ heat-inactivated FBS and $100 \mu \mathrm{g} / \mathrm{ml}$ of penicillin/streptomycin antibiotics in a humidified atmosphere containing $5 \% \mathrm{CO}_{2}$ and $95 \%$ air at $37^{\circ} \mathrm{C}$. The cells were pre-treated with various concentrations $(0-5 \mu \mathrm{M})$ of esculetin for $1 \mathrm{~h}$ and then incubated with or without $1 \mathrm{mM}$ $\mathrm{H}_{2} \mathrm{O}_{2}$ for $6 \mathrm{~h}$ in the absence or presence of $5 \mathrm{mM}$ NAC or $50 \mu \mathrm{M}$ PD98059. To measure cell viability, the cells were maintained with MTT at a final concentration of $0.5 \mathrm{mg} / \mathrm{ml}$ for $3 \mathrm{~h}$, and the formazan that formed was dissolved in DMSO. Optical density was measured at $540 \mathrm{~nm}$ using an enzyme-linked immunosorbent assay (ELISA) plate reader (Dynatech MR-7000; Dynatech Laboratories, Chantilly, VA, USA). The optical density of the formazan formed in the control (untreated) cells was used to represent $100 \%$ viability (36).

Measurement of ROS generation. To measure ROS levels, the cells were washed twice with phosphate-buffered saline (PBS) and lysed with $1 \%$ Triton X-100 in PBS for $10 \mathrm{~min}$ at $37^{\circ} \mathrm{C}$. The cells were pre-treated with $5 \mu \mathrm{M}$ esculetin for $1 \mathrm{~h}$ and then incubated with or without $1 \mathrm{mM} \mathrm{H}_{2} \mathrm{O}_{2}$ for $6 \mathrm{~h}$ in the absence or presence of $5 \mathrm{mM}$ NAC or $50 \mu \mathrm{M}$ PD98059. The cells were then stained with $10 \mu \mathrm{M}$ DCFDA for $20 \mathrm{~min}$ at room temperature in the dark. The green fluorescence of DCF was recorded at $515 \mathrm{~nm}$ using a flow cytometer, and 10,000 events were counted per sample. The results are expressed as the percentage of increase relative to the non-treated cells.

Comet assay (single-cell gel electrophoresis assay). A comet assay was performed to detect DNA migrating from single cells in the gel, following a previously described method (37). Briefly, the cells were exposed to $1 \mathrm{mM} \mathrm{H}_{2} \mathrm{O}_{2}$ for $6 \mathrm{~h}$ in the presence and absence of $5 \mu \mathrm{M}$ esculetin for $1 \mathrm{~h}$. The cells were suspended in $1 \%$ low melting point agarose and aliquoted onto glass microscope slides. The slides were placed in single rows and electrophoresed at $30 \mathrm{~V}(1 \mathrm{~V} / \mathrm{cm})$ and $300 \mathrm{~mA}$ for 20 min to draw negatively charged DNA toward the anode. Finally, the slides were washed with $0.4 \mathrm{M}$ Tris $(\mathrm{pH} 7.5)$ at $4^{\circ} \mathrm{C}$ and stained with $20 \mu \mathrm{g} / \mathrm{ml}$ PI. The slides were examined under a fluorescence microscope (Carl Zeiss AG, Oberkochen, Germany), and the resulting images were analyzed.

Western blot analysis. The cells were pre-treated with $5 \mu \mathrm{M}$ esculetin for $1 \mathrm{~h}$ and then incubated with or without $1 \mathrm{mM}$ $\mathrm{H}_{2} \mathrm{O}_{2}$ for $6 \mathrm{~h}$, or pre-treated with or without $50 \mu \mathrm{M}$ PD98059 for $1 \mathrm{~h}$ and then treated with $5 \mu \mathrm{M}$ esculetin for $4 \mathrm{~h}$. The cells were harvested, washed with PBS, and lysed on ice for $30 \mathrm{~min}$ in lysis buffer (20 mM sucrose, $1 \mathrm{mM}$ ethylenediaminetetraacetic acid, $20 \mu \mathrm{M}$ Tris- $\mathrm{HCl}, \mathrm{pH} 7.2,1 \mathrm{mM}$ dithiothreitol, $10 \mathrm{mM} \mathrm{KCl}$, $1.5 \mathrm{mM} \mathrm{MgCl}_{2}$, and $5 \mu \mathrm{g} / \mathrm{ml}$ aprotinin). Subsequently, an equal amount of protein for each sample was separated by sodium dodecyl sulfate (SDS)-polyacrylamide gel electrophoresis and transferred to polyvinylidene fluoride membranes (Schleicher $\&$ Schuell, Inc., Keene, NH, USA). The membranes were blocked with $5 \%$ skim milk and then incubated overnight at $4^{\circ} \mathrm{C}$ with desired primary antibodies. The membranes were further incubated with corresponding HRP-conjugated secondary antibodies for $2 \mathrm{~h}$ at room temperature. The proteins of interest were visualized using an ECL detection system. 
Table I. Antibodies used in the present study.

\begin{tabular}{lllc}
\hline Antibody & \multicolumn{1}{c}{ Origin } & \multicolumn{1}{c}{ Company } & Catalogue no. \\
\hline Actin & Mouse monoclonal & Santa Cruz Biotechnology, Inc. & SC-47778 \\
p- $\gamma$ H2AX & Rabbit monoclonal & Cell Signaling Technology, Inc. & 9718 \\
$\gamma$ H2AX & Rabbit monoclonal & Cell Signaling Technology, Inc. & 7631 \\
PARP & Rabbit polyclonal & Santa Cruz Biotechnology, Inc. & SC-7150 \\
p-Nrf2 & Rabbit monoclonal & Abcam, Inc. & ab76026 \\
Nrf2 & Rabbit polyclonal & Santa Cruz Biotechnology, Inc. & SC-13032 \\
Keap1 & Goat polyclonal & Santa Cruz Biotechnology, Inc. & SC-15246 \\
HO-1 & Rabbit polyclonal & Santa Cruz Biotechnology, Inc. & SC-10789 \\
NQO1 & Goat polyclonal & Santa Cruz Biotechnology, Inc. & SC-16464 \\
p-ERK & Mouse monoclonal & Cell Signaling Technology, Inc. & 9106 \\
ERK & Rabbit polyclonal & Santa Cruz Biotechnology, Inc. & SC-154 \\
p-JNK & Mouse monoclonal & Cell Signaling Technology, Inc. & 9255 \\
JNK & Rabbit monoclonal & Cell Signaling Technology, Inc. & 9252 \\
p-p38 MAPK & Rabbit monoclonal & Cell Signaling Technology, Inc. & 9211 \\
p38 MAPK & Rabbit polyclonal & Santa Cruz Biotechnology, Inc. & SC-535
\end{tabular}

Detection of nuclear morphological changes. The cells were pre-treated with $5 \mu \mathrm{M}$ esculetin for $1 \mathrm{~h}$ and then incubated with or without $1 \mathrm{mM} \mathrm{H}_{2} \mathrm{O}_{2}$ for $6 \mathrm{~h}$. The detection of chromatin condensation and nuclear fragmentation in the nuclei of apoptotic cells was performed using DAPI staining. The cells were harvested, washed with PBS twice, and fixed with $3.7 \%$ paraformaldehyde in PBS for $10 \mathrm{~min}$ at $25^{\circ} \mathrm{C}$. The fixed cells were washed with PBS and stained with $1 \mathrm{mg} / \mathrm{ml}$ DAPI solution for $10 \mathrm{~min}$. The cells were then washed twice with PBS and observed under a fluorescence microscope (38).

Flow cytometric detection of apoptosis. The cells were pre-treated for $1 \mathrm{~h}$ with the indicated concentrations of esculetin and then incubated for $6 \mathrm{~h}$ with or without $1 \mathrm{mM} \mathrm{H}_{2} \mathrm{O}_{2}$ in the absence or presence of $50 \mu \mathrm{M}$ PD98059. The rate of apoptosis was determined using an Annexin V-FITC apoptosis detection kit. After treatment with the agents, the cells in each sample were stained with Annexin V-FITC and PI in accordance with the manufacturer's instructions. After a 15-min incubation at room temperature in the dark, the degree of apoptosis was quantified as a percentage of the Annexin V-positive and PI-negative (Annexin $\mathrm{V}^{+} / \mathrm{PI}^{-}$cells) cells using a flow cytometer (Becton Dickinson, San Jose, CA, USA) (39).

Statistical analysis. Unless specified otherwise, data are expressed as the means \pm standard deviation (SD) of at least three independent experiments. A one-way analysis of variance (SPSS version 12.0 software) and a Scheffe's test were used to determine the significance of differences between groups. $\mathrm{P}<0.05$ was considered to indicate a statistically significant difference.

\section{Results}

Effects of esculetin on $\mathrm{H}_{2} \mathrm{O}_{2}$-induced cytotoxicity in $\mathrm{C} 2 \mathrm{Cl}$ cells. To determine the protective effects of esculetin against $\mathrm{H}_{2} \mathrm{O}_{2}$-induced cytotoxicity, $\mathrm{C} 2 \mathrm{C} 12$ cells were pre-treated with various concentrations of esculetin $(1.25-5 \mu \mathrm{M})$ for $1 \mathrm{~h}$ and then exposed to $\mathrm{H}_{2} \mathrm{O}_{2}(1 \mathrm{mM})$ for a further $6 \mathrm{~h}$. The

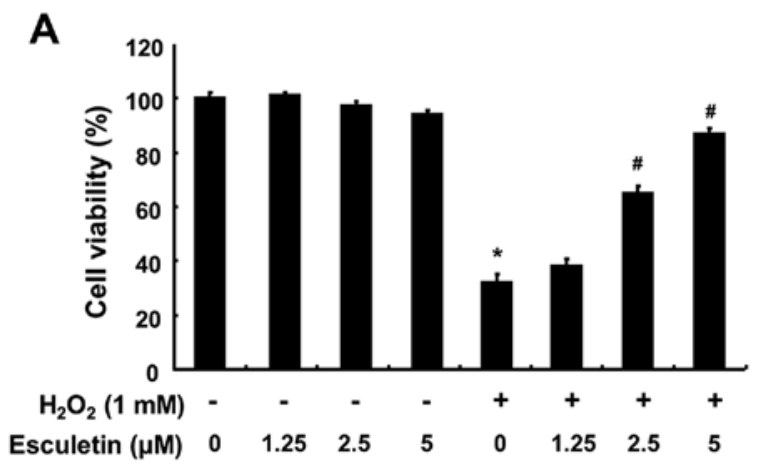

B

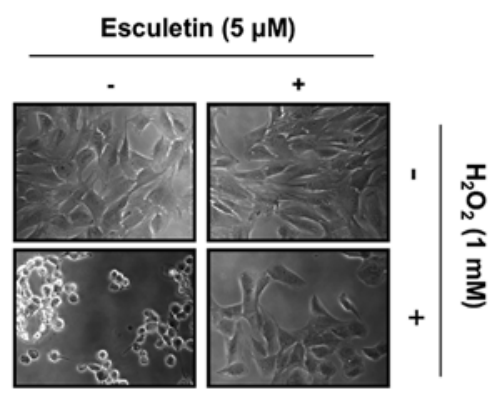

Figure 1. Esculetin inhibits $\mathrm{H}_{2} \mathrm{O}_{2}$-induced cytotoxicity in $\mathrm{C} 2 \mathrm{C} 12$ cells. The cells were pre-treated with the indicated concentrations of esculetin (A) or $5 \mu \mathrm{M}$ esculetin (B) for $1 \mathrm{~h}$ and then incubated without or with $1 \mathrm{mM} \mathrm{H}_{2} \mathrm{O}_{2}$ for $6 \mathrm{~h}$. The cell viability was assessed using an MTT reduction assay. The results were the mean \pm SD values obtained in three independent experiments $\left({ }^{*} \mathrm{P}<0.05\right.$ compared with the control group; ${ }^{*} \mathrm{P}<0.05$ compared with the $\mathrm{H}_{2} \mathrm{O}_{2}$-treated group). (B) Cellular morphological changes were monitored by obtaining photomicrographs under an inverted phase contrast microscope (x200). $\mathrm{H}_{2} \mathrm{O}_{2}$, hydrogen peroxide.

concentrations of esculetin that did not have any measurable adverse effects on the cells were selected (data not shown). As shown in Fig. 1A, exposure to $\mathrm{H}_{2} \mathrm{O}_{2}$ alone significantly reduced cell viability (more than 60\%) when measured using the MTT assay, whereas the $\mathrm{H}_{2} \mathrm{O}_{2}$-induced reduction in cell viability was prevented by pre-treatment with esculetin 


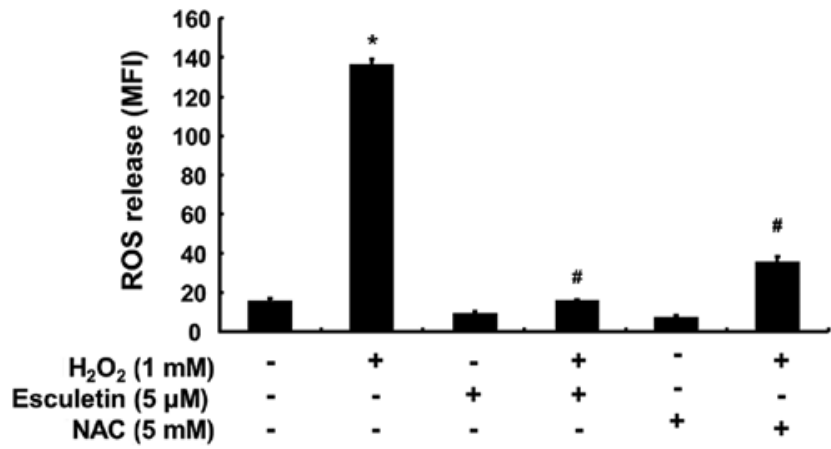

Figure 2. Inhibition of $\mathrm{H}_{2} \mathrm{O}_{2}$-induced ROS generation by esculetin in $\mathrm{C} 2 \mathrm{C} 12$ cells. The cells were pre-treated with $5 \mu \mathrm{M}$ esculetin or $5 \mathrm{mM} \mathrm{NAC}$ for $1 \mathrm{~h}$ and then incubated with and without $1 \mathrm{mM} \mathrm{H}_{2} \mathrm{O}_{2}$ for $6 \mathrm{~h}$. To monitor ROS production, the cells were incubated at $37^{\circ} \mathrm{C}$ in the dark for 20 min with new culture medium containing $10 \mu \mathrm{M}$ DCFDA. ROS accumulation was measured using a flow cytometer. The results were the mean \pm SD values obtained in three independent experiments $\left({ }^{*} \mathrm{P}<0.05\right.$ compared with the control group; ${ }^{\#} \mathrm{P}<0.05$ compared with the $\mathrm{H}_{2} \mathrm{O}_{2}$-treated group). $\mathrm{H}_{2} \mathrm{O}_{2}$, hydrogen peroxide; ROS, reactive oxygen species; NAC, $N$-acetyl-L-cysteine; DCFDA, dichlorofluorescein diacetate.

A

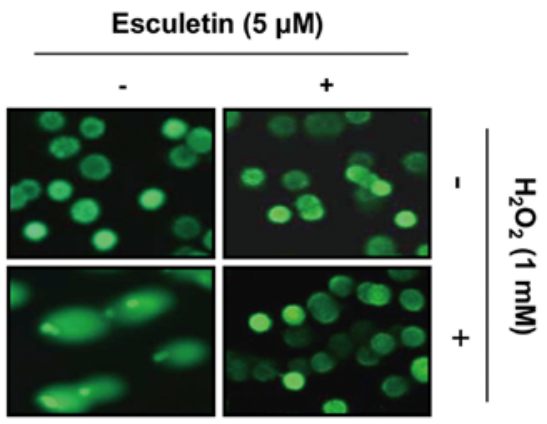

B

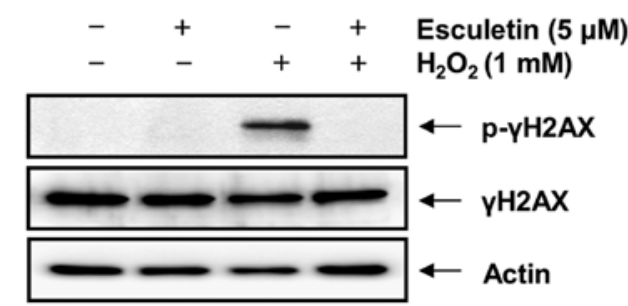

Figure 3. Inhibition of $\mathrm{H}_{2} \mathrm{O}_{2}$-induced DNA damage by esculetin in $\mathrm{C} 2 \mathrm{C} 12$ cells. The cells were pre-treated with $5 \mu \mathrm{M}$ esculetin for $1 \mathrm{~h}$ and then incubated without or with $1 \mathrm{mM} \mathrm{H}_{2} \mathrm{O}_{2}$ for $6 \mathrm{~h}$. (A) To detect cellular DNA damage, the comet assay was performed, and representative images of the comets were taken using a fluorescence microscope (x200 original magnification). (B) The cells were lysed and then equal amounts of cell lysates ( $30 \mu \mathrm{g})$ were separated on SDS-polyacrylamide gels and transferred to membranes. The membranes were probed with specific antibodies against $p-\gamma \mathrm{H} 2 \mathrm{AX}, \gamma \mathrm{H} 2 \mathrm{AX}$, and actin as an internal control, and the proteins were visualized using an ECL detection system. $\mathrm{H}_{2} \mathrm{O}_{2}$, hydrogen peroxide; SDS, sodium dodecyl sulfate; ECL, enhanced chemiluminescence.

in a concentration-dependent manner. In addition, $\mathrm{H}_{2} \mathrm{O}_{2}$ stimulation significantly induced morphological changes, including extensive cytosolic vacuolization and the presence of irregular cell membrane buds, which were effectively attenuated by esculetin pre-treatment (Fig. 1B).

Inhibition of $\mathrm{H}_{2} \mathrm{O}_{2}$-induced $\mathrm{ROS}$ generation by esculetin in C2C12 cells. The intracellular ROS generation was monitored
A

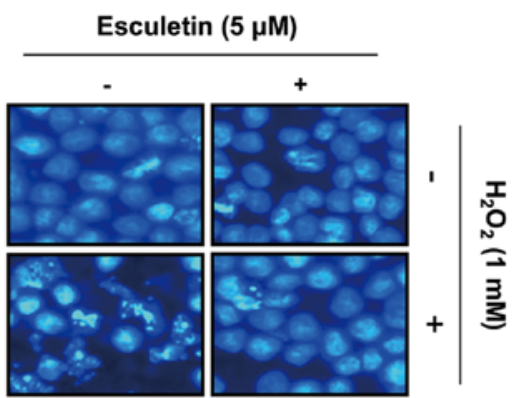

B

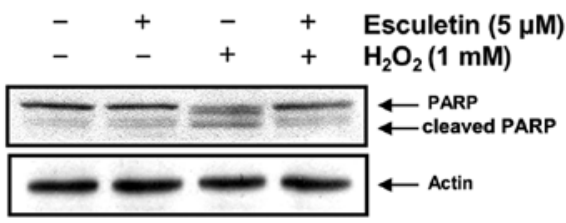

C

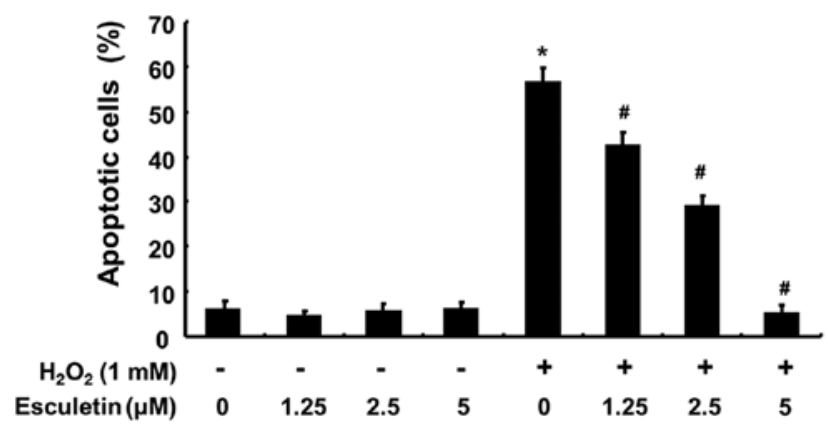

Figure 4. Protection against $\mathrm{H}_{2} \mathrm{O}_{2}$-induced apoptosis by esculetin in $\mathrm{C} 2 \mathrm{C} 12$ cells. The cells were pre-treated with the indicated concentrations of esculetin for $1 \mathrm{~h}$ and then incubated without or with $1 \mathrm{mM} \mathrm{H}_{2} \mathrm{O}_{2}$ for $6 \mathrm{~h}$. (A) The cells were fixed and stained with DAPI solution. The stained nuclei were observed under a fluorescence microscope (x400 original magnification) (B) Cellular proteins were separated on SDS-polyacrylamide gels and were subsequently transferred onto nitrocellulose membranes. The membranes were probed with an antibody against PARP. Proteins were visualized using an ECL detection system. Actin was used as an internal control. (C) To quantify the degree of apoptosis, the cells were stained with Annexin V-FITC and PI for flow cytometric analysis. The results are expressed as the mean \pm SD values obtained in three independent experiments ( $\mathrm{P}<0.05$ compared with the control group; ${ }^{\prime} \mathrm{P}<0.05$ compared with the $\mathrm{H}_{2} \mathrm{O}_{2}$-treated group). $\mathrm{H}_{2} \mathrm{O}_{2}$, hydrogen peroxide; DAPI, 4',6-diamidino-2-phenylindole; SDS, sodium dodecyl sulfate; PARP, poly(ADP ribose) polymerase; ECL, enhanced chemiluminescence; FITC, fluorescein isothiocyanate; PI, propidium iodide.

to investigate whether esculetin can prevent $\mathrm{H}_{2} \mathrm{O}_{2}$-induced $\mathrm{ROS}$ generation. The results of the flow cytometric analysis using DCFDA as a fluorescence probe demonstrated that the intensity of the DCF-liberated fluorescent signal from the $\mathrm{H}_{2} \mathrm{O}_{2}$-exposed cells was significantly increased; however, the signal was markedly reduced in the presence of $5 \mu \mathrm{M}$ esculetin (Fig. 2). As a positive control, the ROS scavenger NAC at $5 \mathrm{mM}$ also markedly attenuated $\mathrm{H}_{2} \mathrm{O}_{2}$-induced ROS generation, indicating that esculetin scavenged $\mathrm{H}_{2} \mathrm{O}_{2}$-induced ROS accumulation.

Esculetin protects $\mathrm{C} 2 \mathrm{Cl} 2$ cells from $\mathrm{H}_{2} \mathrm{O}_{2}$-induced DNA damage. We then examined the effects of esculetin on $\mathrm{H}_{2} \mathrm{O}_{2}$-mediated DNA damage in $\mathrm{C} 2 \mathrm{C} 12$ cells. Fig. 3A shows the results of the comet assay performed to evaluate the protective effect of esculetin against $\mathrm{H}_{2} \mathrm{O}_{2}$-induced DNA damage. Exposure to 


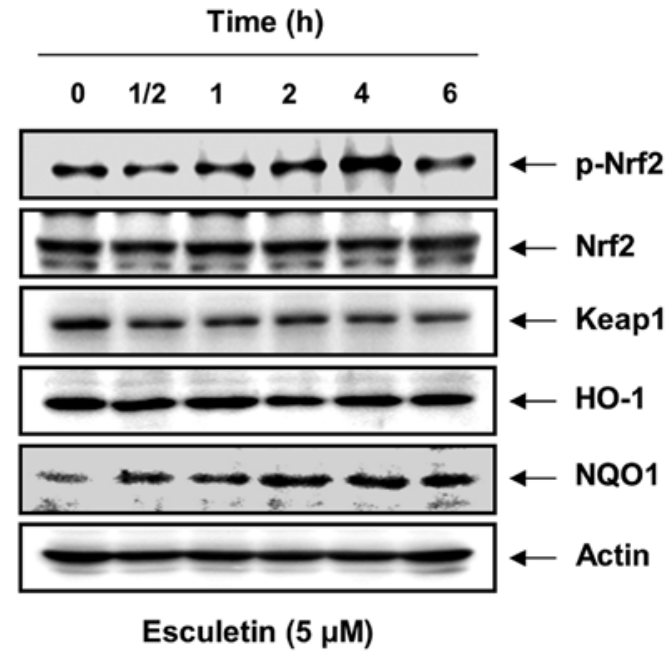

Figure 5. Effects of esculetin on the expression of Nrf2, Keap1, HO-1, and NQO1 in C2C12 cells. The cells were incubated with $5 \mu \mathrm{M}$ esculetin for the indicated time periods. Cellular proteins were separated on SDS-polyacrylamide gels and then transferred onto membranes. The membranes were probed with specific antibodies against Nrf2, p-Nrf2, Keap1, HO-1, and NQO1. Proteins were visualized using an ECL detection system. Actin was used as an internal control. Nrf2, nuclear factor erythroid 2-related factor 2; Keap1, Kelch-like ECH-associated protein 1; HO-1, heme oxygenase-1; NQO1, NAD(P)H:quinone oxidoreductase 1; SDS, sodium dodecyl sulfate; ECL, enhanced chemiluminescence.

$\mathrm{H}_{2} \mathrm{O}_{2}$ leads to the loss of membrane integrity; therefore, the fragmented DNA appeared outside the cell as comet-like structures; however, this adverse effect was markedly inhibited by esculetin. In addition, treatment of the $\mathrm{C} 2 \mathrm{C} 12$ cells with $\mathrm{H}_{2} \mathrm{O}_{2}$ upregulated the level of the phosphorylated histone variant $\mathrm{H} 2 \mathrm{AX}$ at serine 139 (p- $\gamma \mathrm{H} 2 \mathrm{AX})$, a sensitive marker of DNA double-strand breaks (40) (Fig. 3B). However, pre-treatment with esculetin significantly decreased $\mathrm{H}_{2} \mathrm{O}_{2}$-induced $\mathrm{p}-\gamma \mathrm{H} 2 \mathrm{AX}$ expression.

Inhibition of the $\mathrm{H}_{2} \mathrm{O}_{2}$-induced apoptosis of $\mathrm{C} 2 \mathrm{Cl} 2$ cells by esculetin. To evaluate the potential effect of esculetin on $\mathrm{H}_{2} \mathrm{O}_{2}$-induced $\mathrm{C} 2 \mathrm{C} 12$ cell apoptosis, we examined apoptotic features by measuring chromatin condensation in the nuclei, poly(ADP ribose) polymerase (PARP) cleavage, and Annexin V-positive cells. DAPI staining revealed increased nuclei with chromatin condensation and the formation of apoptotic bodies, characteristic morphological changes of apoptosis, in cells cultured with $1 \mathrm{mM} \mathrm{H}_{2} \mathrm{O}_{2}$. However, the control and esculetin $(5 \mu \mathrm{M})$-treated groups showed few apoptotic cells, and pre-treatment of the cells with esculetin significantly abrogated the $\mathrm{H}_{2} \mathrm{O}_{2}$-induced apoptotic characteristics (Fig. 4A). The results of western blot analysis also indicated a marked increase in the level of cleaved PARP, an apoptotic marker protein, in the $\mathrm{H}_{2} \mathrm{O}_{2}$-treated cells compared with the control group, and treatment with esculetin significantly decreased the levels of cleaved PARP (Fig. 4B). Furthermore, the results of flow cytometric analysis revealed an increase in the percentage of Annexin-positive $\mathrm{C} 2 \mathrm{C} 12$ cells exposed to $\mathrm{H}_{2} \mathrm{O}_{2}$ compared with the cells in the control group. By contrast, treatment of the cells with esculetin prior to exposure to $\mathrm{H}_{2} \mathrm{O}_{2}$ strongly protected the $\mathrm{C} 2 \mathrm{C} 12$ cells against apoptosis in a concentration-dependent manner (Fig. 4C). These results clearly indicated that esculetin inhibited $\mathrm{H}_{2} \mathrm{O}_{2}$-induced apoptotic signaling in the $\mathrm{H}_{2} \mathrm{O}_{2}$-exposed $\mathrm{C} 2 \mathrm{C} 12$ cells.
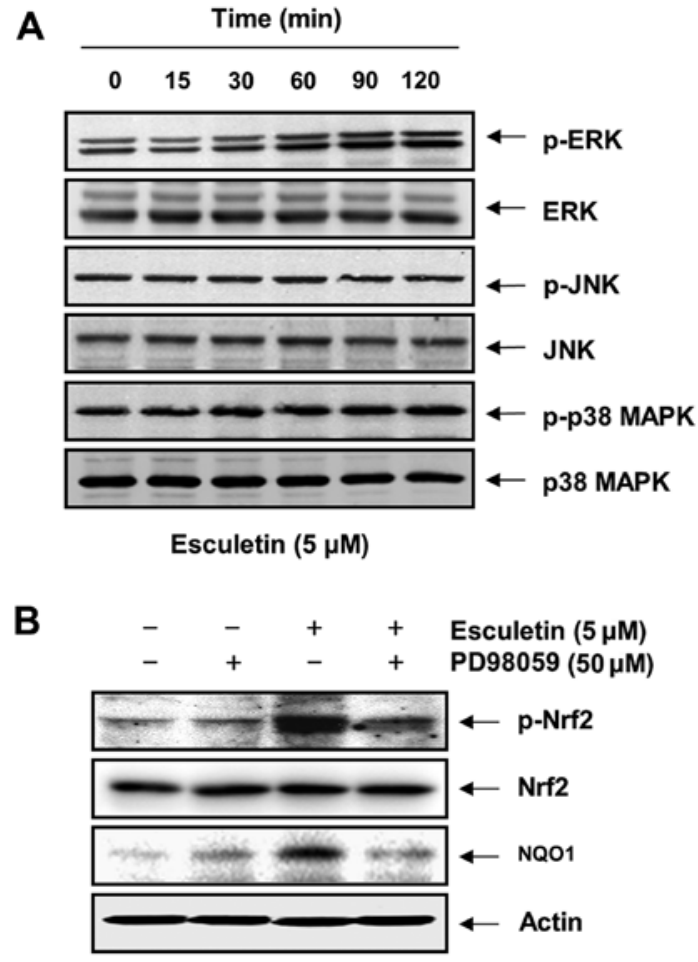

Figure 6. Involvement of the ERK signaling pathway in the phosphorylation of Nrf2 and induction of NQO1 by esculetin in $\mathrm{C} 2 \mathrm{C} 12$ cells. Cells were treated with $5 \mu \mathrm{M}$ esculetin for the indicated times (A) or pre-treated for $1 \mathrm{~h}$ without or with $50 \mu \mathrm{M}$ PD98059, an ERK inhibitor, and then treated with $5 \mu \mathrm{M}$ esculetin for an additional $4 \mathrm{~h}$ (B). The cells were lysed, and then equal amounts of cell lysates were separated on SDS-polyacrylamide gels and transferred to nitrocellulose membranes. The membranes were probed with the indicated antibodies, and the proteins were visualized using an ECL detection system. Actin was used as an internal control. ERK, extracellular signal-regulated kinase; Nrf2, nuclear factor erythroid 2-related factor 2; NQO1, NAD(P) H:quinone oxidoreductase 1; ECL, enhanced chemiluminescence.

Induction of $\mathrm{Nrf} 2$ and $\mathrm{NQO1}$ expression by esculetin in $\mathrm{C} 2 \mathrm{C} 12$ cells. To determine whether the protective effects of esculetin against $\mathrm{H}_{2} \mathrm{O}_{2}$-induced oxidative stress and apoptosis result from the induction of the expression of antioxidant genes, such as HO-1 and NQO1, and their transcription factor Nrf2, western blot analysis was performed. As shown in Fig. 5, the esculetin-treated cells exhibited a significant increase in the protein levels of NQO1 compared to these levels in the control group; however, no changes were observed in the levels of HO-1. Furthermore, esculetin enhanced the phosphorylated levels of endogenous Nrf2 in a time-dependent manner without affecting their total steady-state levels and obtained greatest induction at $5 \mu \mathrm{M}$ after $4 \mathrm{~h}$. By contrast, esculetin reduced the levels of Keap1 under the same conditions.

Phosphorylation of Nrf 2 by esculetin through the activation of extracellular signal-regulated kinase (ERK) in C2C12 cells. To investigate whether Nrf2 phosphorylation by esculetin in $\mathrm{C} 2 \mathrm{C} 12$ cells is affected by the activation of MAPKs as upstream signaling mediators, we assessed the phosphorylated forms of ERK, JNK and p38 MAPK. As shown in Fig. 6A, although the total protein levels of ERK did not show notable changes, esculetin markedly increased the phosphorylation of ERK within $1 \mathrm{~h}$ of treatment, while the phosphorylation levels of JNK and p38 MAPK remained 
A

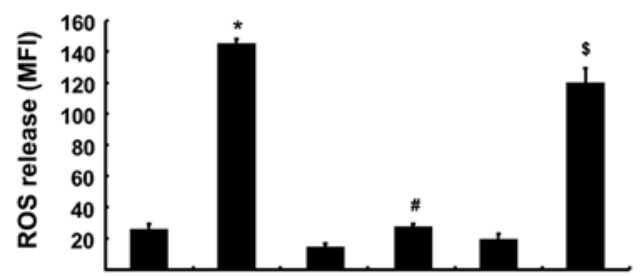

B
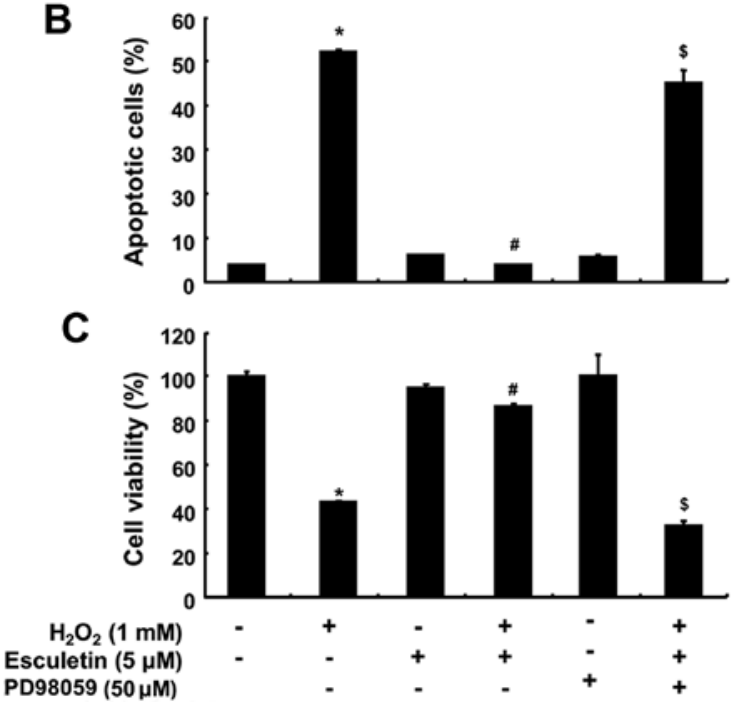

Figure 7. Effects of an ERK inhibitor on esculetin-mediated attenuation of ROS formation, apoptosis and growth inhibition by $\mathrm{H}_{2} \mathrm{O}_{2}$ in $\mathrm{C} 2 \mathrm{C} 12$ cells. The cells were pre-treated for $1 \mathrm{~h}$ with $5 \mu \mathrm{M}$ esculetin and were subsequently treated for $6 \mathrm{~h}$ with or without $1 \mathrm{mM} \mathrm{H}_{2} \mathrm{O}_{2}$ in the absence or presence of $50 \mu \mathrm{M}$ PD98059. ROS generation (A), apoptosis rate (B) and cell viability (C) were estimated, respectively. The results are expressed as the mean \pm SD values obtained in three independent experiments $\left({ }^{*} \mathrm{P}<0.05\right.$ compared with the control group; ${ }^{\#} \mathrm{P}<0.05$ compared with the $\mathrm{H}_{2} \mathrm{O}_{2}$-treated group; ${ }^{\mathrm{P}} \mathrm{P}<0.05$ compared with the $\mathrm{H}_{2} \mathrm{O}_{2}$ and esculetin treated group). ERK, extracellular signal-regulated kinase; ROS, reactive oxygen species; $\mathrm{H}_{2} \mathrm{O}_{2}$, hydrogen peroxide.

unaltered. The dependence of the phosphorylation of Nrf2 challenged with esculetin upon the activation of ERK was confirmed using a specific inhibitor of ERK, PD98059. For this experiment, the $\mathrm{C} 2 \mathrm{C} 12$ cells were pre-treated with $50 \mu \mathrm{M}$ PD98059 for $1 \mathrm{~h}$ and then treated with esculetin for $4 \mathrm{~h}$. We found that treatment with PD98059 effectively reduced the esculetin-induced phosphorylation of Nrf2, with a resulting decrease in the expression of NQO1 (Fig. 6B). In addition, co-pre-treatment with PD98059 and esculetin prior to exposure to $\mathrm{H}_{2} \mathrm{O}_{2}$ markedly abrogated the protective effects of esculetin against $\mathrm{H}_{2} \mathrm{O}_{2}$-induced ROS generation and apoptosis as well as growth reduction (Fig. 7).

\section{Discussion}

Many recent studies have reported that natural compounds have broad protective effects against oxidative stress. Moreover, the removal of excess ROS or the suppression of their generation by antioxidants may be effective in preventing oxidative DNA damage and cell death $(6,7)$. In this study, esculetin showed intracellular ROS scavenging activities and provided cytoprotection against oxidative stress in $\mathrm{C} 2 \mathrm{C} 12$ cells (Figs. 1 and 2), suggesting that it may be involved in the activation of antioxidant enzymes. Our data also demonstrated that esculetin effectively protected $\mathrm{C} 2 \mathrm{C} 12$ cells from $\mathrm{H}_{2} \mathrm{O}_{2}$-mediated DNA damage and apoptosis (Figs. 3 and 4).

Accumulating evidence indicates that the transcription factor Nrf2 may serve as a critical regulator of the cellular antioxidant response to protect against oxidative stress-induced DNA damage and apoptosis $(9,10)$. When stimulated by inducers, $\mathrm{Nrf} 2$ is released from Keap1, leading to phosphorylation of Nrf2, which is a critical process in the nuclear translocation of Nrf2 (41-43). In the nucleus, Nrf2 dimerizes with other cofactors and binds AREs to induce detoxification enzymes and antioxidant proteins in response to a number of stimuli, including oxidative stress $(11,15)$. Therefore, we selected phase- 2 antioxidative enzymes such as HO-1 and NQO1 and ascertained whether they would be regulated via the Nrf2 signaling pathway in $\mathrm{H}_{2} \mathrm{O}_{2}$-induced $\mathrm{C} 2 \mathrm{C} 12$ cell damage and esculetin-mediated cytoprotection. The results demonstrated that esculetin induced the phosphorylation of Nrf2 and the expression of NQO1 but not HO-1, along with the downregulation of Keap1 expression (Fig. 5), which is consistent with a previous study (24). These results indicate that esculetin may stimulate Nrf2 activation by enhancing Nrf2 phosphorylation and reducing Keap1 at the same time, in other words by increasing the ratio of Nrf2/Keap1.

Several reports have suggested that the MAPK signaling pathway is a central regulatory pathway for Nrf2 phosphorylation and nuclear translocation associated with inducible expression of antioxidant enzymes $(42,43)$. To further identify the signaling pathways affected by esculetin that enhance Nrf2 phosphorylation and NQO1 expression, we investigated the effects of esculetin on three MAPK cascades. Immunoblotting data indicated that phosphorylation of ERK occurred at $30 \mathrm{~min}$ after esculetin treatment and was sustained for up to $120 \mathrm{~min}$, while JNK and ERK were not affected (Fig. 6A). Moreover, esculetin induced the phosphorylation of Nrf2 and NQO1 expression was markedly suppressed by PD98059, a specific inhibitor of ERK (Fig. 6B). These observations suggest that ERK appears to play a major role and upregulated Nrf2 phosphorylation in the induction of downstream NQO1 expression in esculetin-treated $\mathrm{C} 2 \mathrm{C} 12$ cells. In parallel with these observations, we also found that blockage of ERK activation with PD98059 markedly abrogated the protective effects of esculetin against $\mathrm{H}_{2} \mathrm{O}_{2}$-induced ROS generation, apoptosis, and inhibition of the growth of the $\mathrm{C} 2 \mathrm{C} 12$ cells (Fig. 7). The data provide positive evidence that the ERK signaling pathway is involved in the esculetin-mediated activation of $\mathrm{Nrf} 2$ and upregulation of NQO1; therefore, regulation of the Nrf2/NQO1 pathway can reduce $\mathrm{H}_{2} \mathrm{O}_{2}$-induced oxidative damage in $\mathrm{C} 2 \mathrm{C} 12$ cells.

Taken together, the present results demonstrated that esculetin exhibits potent cytoprotective effects against cell toxicity resulting from exposure to $\mathrm{H}_{2} \mathrm{O}_{2}$ via scavenging ROS. Moreover, the phosphorylation of Nrf2 and upregulation of NQO1 via ERK signaling are critical for protection against $\mathrm{H}_{2} \mathrm{O}_{2}$-induced oxidative stress. Although further research and clinical trials are needed to further elucidate the molecular mechanisms detected herein, the findings of our study suggest that esculetin has potential therapeutic value as an antioxidant agent.

\section{Acknowledgements}

This research was supported by Basic Science Research Program through the National Research Foundation of 
Korea (NRF) grant funded by the Korea government (nos. 2015R1A2A1A10051603 and 2015R1A2A2A01004633).

\section{References}

1. Lyakhovich A and Graifer D: Mitochondria-mediated oxidative stress: Old target for new drugs. Curr Med Chem 22: 3040-3053, 2015.

2. Ermakov AV, Konkova MS, Kostyuk SV, Izevskaya VL, Baranova A and Veiko NN: Oxidized extracellular DNA as a stress signal in human cells. Oxid Med Cell Longev 2013: 649747, 2013.

3. Dai DF, Chiao YA, Marcinek DJ, Szeto HH and Rabinovitch PS Mitochondrial oxidative stress in aging and healthspan. Longev Healthspan 3: 6, 2014.

4. Brieger K, Schiavone S, Miller FJ Jr and Krause KH: Reactive oxygen species: From health to disease. Swiss Med Wkly 142: w13659, 2012.

5. Mena S, Ortega A and Estrela JM: Oxidative stress in environmental-induced carcinogenesis. Mutat Res 674: 36-44, 2009.

6. Rajendran P, Nandakumar N, Rengarajan T, Palaniswami R, Gnanadhas EN, Lakshminarasaiah U, Gopas J and Nishigaki I: Antioxidants and human diseases. Clin Chim Acta 436: 332-347, 2014.

7. Yang HY and Lee TH: Antioxidant enzymes as redox-based biomarkers: A brief review. BMB Rep 48: 200-208, 2015.

8. Silva-Palacios A, Königsberg M and Zazueta C: Nrf2 signaling and redox homeostasis in the aging heart: A potential target to prevent cardiovascular diseases? Ageing Res Rev 26: 81-95, 2016

9. Huang Y, Li W, Su ZY and Kong AN: The complexity of the Nrf2 pathway: Beyond the antioxidant response. J Nutr Biochem 26 : $1401-1413,2015$.

10. Gan L and Johnson JA: Oxidative damage and the Nrf2-ARE pathway in neurodegenerative diseases. Biochim Biophys Acta 1842: 1208-1218, 2014

11. Suzuki T and Yamamoto M: Molecular basis of the Keap1-Nrf2 system. Free Radic Biol Med 88: 93-100, 2015.

12. O'Connell MA and Hayes JD: The Keap1/Nrf2 pathway in health and disease: From the bench to the clinic. Biochem Soc Trans 43 : 687-689, 2015.

13. Jaramillo MC and Zhang DD: The emerging role of the Nrf2-Keap1 signaling pathway in cancer. Genes Dev 27: 2179-2191,2013.

14. Murakami S and Motohashi $\mathrm{H}$ : Roles of Nrf2 in cell proliferation and differentiation. Free Radic Biol Med 88: 168-178, 2015.

15. Stefanson AL and Bakovic M: Dietary regulation of Keap1/Nrf2/ARE pathway: Focus on plant-derived compounds and trace minerals. Nutrients 6: 3777-3801, 2014.

16. Mancuso $\mathrm{C}$ and Barone E: The heme oxygenase/biliverdin reductase pathway in drug research and development. Curr Drug Metab 10: 579-594, 2009.

17. Wegiel B, Nemeth Z, Correa-Costa M, Bulmer AC and Otterbein LE: Heme oxygenase-1: A metabolic Nike. Antioxid Redox Signal 20: 1709-1722, 2014

18. Baulig A, Garlatti M, Bonvallot V, Marchand A, Barouki R, Marano $F$ and Baeza-Squiban A: Involvement of reactive oxygen species in the metabolic pathways triggered by diesel exhaust particles in human airway epithelial cells. Am J Physiol Lung Cell Mol Physiol 285: L671-L679, 2003.

19. Piao MS, Choi JY, Lee DH, Yun SJ, Lee JB and Lee SC: Differentiation-dependent expression of NADP $(H)$ :quinone oxidoreductase-1 via NF-E2 related factor-2 activation in human epidermal keratinocytes. J Dermatol Sci 62: 147-153, 2011.

20. Fylaktakidou KC, Hadjipavlou-Litina DJ, Litinas KE and Nicolaides DN: Natural and synthetic coumarin derivatives with anti-inflammatory/antioxidant activities. Curr Pharm Des 10: 3813-3833, 2004.

21. Lacy A and O'Kennedy R: Studies on coumarins and coumarin-related compounds to determine their therapeutic role in the treatment of cancer. Curr Pharm Des 10: 3797-3811, 2004.

22. Chang WS, Lin CC, Chuang SC and Chiang HC: Superoxide anion scavenging effect of coumarins. Am J Chin Med 24: 11-17, 1996.

23. Hu J, Zhu Q, Bai S and Jia Z: New eudesmane sesquiterpene and other constituents from Artemisia mongolica. Planta Med 62: 477-478, 1996
24. Subramaniam SR and Ellis EM: Esculetin-induced protection of human hepatoma HepG2 cells against hydrogen peroxide is associated with the Nrf2-dependent induction of the NAD $(\mathrm{P}) \mathrm{H}$ : quinone oxidoreductase 1 gene. Toxicol Appl Pharmacol 250: 130-136, 2011.

25. Lee CR, Shin EJ, Kim HC, Choi YS, Shin T and Wie MB: Esculetin inhibits $N$-methyl-D-aspartate neurotoxicity via glutathione preservation in primary cortical cultures. Lab Anim Res 27: 259-263, 2011.

26. Park SL, Won SY, Song JH, Lee SY, Kim WJ and Moon SK: Esculetin inhibits VEGF-induced angiogenesis both in vitro and in vivo. Am J Chin Med 44: 61-76, 2016.

27. Zhu L, Nang C, Luo F, Pan H, Zhang K, Liu J, Zhou R, Gao J, Chang $\mathrm{X}, \mathrm{He} \mathrm{H}$, et al: Esculetin attenuates lipopolysaccharide (LPS)-induced neuroinflammatory processes and depressive-like behavior in mice. Physiol Behav 163: 184-192, 2016.

28. Hong SH, Jeong HK, Han MH, Park C and Choi YH: Esculetin suppresses lipopolysaccharide-induced inflammatory mediators and cytokines by inhibiting nuclear factor- $\mathrm{kB}$ translocation in RAW 264.7 macrophages. Mol Med Rep 10: 3241-3246, 2014.

29. Jeon YJ, Cho JH, Lee SY, Choi YH, Park H, Jung S, Shim JH and Chae JI: Esculetin induces apoptosis through EGFR/PI3K/Akt signaling pathway and nucleophosmin relocalization. J Cell Biochem 117: 1210-1221, 2016.

30. Lee SY, Lim TG, Chen H, Jung SK, Lee HJ, Lee MH, Kim DJ, Shin A, Lee KW, Bode AM, et al: Esculetin suppresses proliferation of human colon cancer cells by directly targeting $\beta$-catenin. Cancer Prev Res (Phila) 6: 1356-1364, 2013.

31. Park C, Jin CY, Kim GY, Choi IW, Kwon TK, Choi BT, Lee SJ, Lee WH and Choi YH: Induction of apoptosis by esculetin in human leukemia U937 cells through activation of JNK and ERK. Toxicol Appl Pharmacol 227: 219-228, 2008.

32. Park C, Jin CY, Kwon HJ, Hwang HJ, Kim GY, Choi IW, Kwon TK, Kim BW, Kim WJ and Choi YH: Induction of apoptosis by esculetin in human leukemia U937 cells: Roles of Bcl-2 and extracellular-regulated kinase signaling. Toxicol In Vitro 24: 486-494, 2010

33. Sulakhiya K, Keshavlal GP, Bezbaruah BB, Dwivedi S, Gurjar SS, Munde N, Jangra A, Lahkar M and Gogoi R: Lipopolysaccharide induced anxiety- and depressive-like behaviour in mice are prevented by chronic pre-treatment of esculetin. Neurosci Lett 611: 106-111, 2016

34. Kim JH, Jeong MS, Kim DY, Her S and Wie MB: Zinc oxide nanoparticles induce lipoxygenase-mediated apoptosis and necrosis in human neuroblastoma SH-SY5Y cells. Neurochem Int 90: 204-214, 2015

35. Prabakaran D and Ashokkumar N: Protective effect of esculetin on hyperglycemia-mediated oxidative damage in the hepatic and renal tissues of experimental diabetic rats. Biochimie 95: 366-373, 2013.

36. Hong SH, Sim MJ and Kim YC: Melanogenesis-promoting effects of Rhynchosia nulubilis and Rhynchosia volubilis ethanol extracts in melan-a cells. Toxicol Res 32: 141-147, 2016.

37. Gunasekarana V, Raj GV and Chand P: A comprehensive review on clinical applications of comet assay. J Clin Diagn Res 9: GE01-GE05, 2015.

38. Zhao X, Sun P, Qian Y and Suo H: D. candidum has in vitro anticancer effects in HCT-116 cancer cells and exerts in vivo anti-metastatic effects in mice. Nutr Res Pract 8: 487-493, 2014.

39. Kwon T, Rho JK, Lee JC, Park YH, Shin HJ, Cho S, Kang YK, Kim Y, Yoon DY and Yu DY: An important role for peroxiredoxin II in survival of A549 lung cancer cells resistant to gefitinib. Exp Mol Med 47: e165, 2015.

40. Rogakou EP, Pilch DR, Orr AH, Ivanova VS and Bonner WM: DNA double-stranded breaks induce histone $\mathrm{H} 2 \mathrm{AX}$ phosphorylation on serine 139. J Biol Chem 273: 5858-5868, 1998.

41. Venugopal R and Jaiswal AK: Nrf1 and Nrf2 positively and c-Fos and Fra1 negatively regulate the human antioxidant response element-mediated expression of NAD $(\mathrm{P}) \mathrm{H}:$ quinone oxidoreductase1 gene. Proc Natl Acad Sci USA 93: 14960-14965, 1996.

42. Kweon MH, Adhami VM, Lee JS and Mukhtar H: Constitutive overexpression of Nrf2-dependent heme oxygenase-1 in A549 cells contributes to resistance to apoptosis induced by epigallocatechin 3-gallate. J Biol Chem 281: 33761-33772, 2006.

43. Surh YJ, Kundu JK and Na HK: Nrf2 as a master redox switch in turning on the cellular signaling involved in the induction of cytoprotective genes by some chemopreventive phytochemicals. Planta Med 74: 1526-1539, 2008. 